\title{
Topical Negative Pressure Therapy and Interactive Dressings in Prevention of Wound Infections in High-Risk Orthopaedic Patients
}

\section{Obolenskiy VN ${ }^{1,2^{*}}$, Golev SN ${ }^{1}$, Zakirov $\|^{3}$ and Semenistyy AA $^{3}$}

${ }^{1}$ State financed health institution City clinical hospital \#13. Board of Health of Moscow, 115280, Moscow, Russian Federation

2State financed educational institution, Higher professional education institution "Pirogov Russian National Research Medical University" N. I. Pirogov" MH RF, 117997,

Moscow, Russian Federation

${ }^{3}$ State financed educational institution Higher professional education institution Peoples' Friendship University of Russia, 117198, Moscow, Russian Federation

\begin{abstract}
The likelihood of periprosthetic infection in high-risk patients (obesity and diabetes mellitus) after revisional arthroplasty is extremely high. The authors conducted a pilot prospective comparative study of clinical and economical efficacy of interactive absorbing dressings based on carboxymethyl cellulose impregnated with silver ions and single-use vacuum assisted dressings in prevention of surface surgical site infections in high-risk patients.
\end{abstract}

Keywords: Periprosthetic infection in high-risk patients; Interactive dressings; Topical negative pressure therapy

\section{Introduction}

Perprosthetic infection is the most common complication and basic issue in replacement arthroplasty [1], "infections associated with total hip replacement are a devastating complication with far reaching consequences both for patients and forhealth care system" [2]. Kuper M. and Rosenstein A. characterized the costs as "mind-boggling" [3], while Rezapoor M. and Parvizi J. predict that in 2015 the U.S. is going to lose 1 billion US dollars to periprosthetic infections. The authors also note that the lethality associated with periprosthetic infections is higher than that of some cancers $[4,5]$.

The incidence of infectious complications occurring after surgical implant placement reaches 3 to 12 per cent [6], while surgical site infections (SSI) following the replacement of big joints is observed in 2.5 per cent of cases [7], in addition, the risk of periprosthetic infection increases 3.3 times in case of revisional prosthetic repair [8]. The number of joint replacement surgeries is on the rise across the world, however the incidence of infectious complications associated with this kind of intervention gains even more momentum [9].

Among the risk factors for periprosthetic infection are immunosuppression, alcohol abuse, systemic use of corticosteroids, inadequate use of antibiotics in disease prevention, obesity, diabetes mellitus, oncological diseases, duration of surgery, intraoperative transfusion of blood components, infectious arthropathies, joint repair and periprosthetic infections in past medical history as well as surface surgical site infections [5,10-18].

Obesity increases the risk of SSI 1.9 times [19], diabetes mellitus raises the same by 2.1 , while compounded effect of both obesity and diabetes leads to 5 times bigger risk of SSI [20].

It is a well-known fact that infected wound complications as well as other iatrogenic complications are easier to prevent than to treat. The most effective prevention methods of periprosthetic infection include rational systemic use of antibiotics, topical use of antibioticimpregnated cement and installation of laminar air supply devices in the operating rooms $[12,21,22]$.

It is also known that the most effective method of prevention and treatment of infected wound complications is topical application of negative pressure - TNP [23-27]. Thus in the study by Condé-Green A [28]. The use of preventative vacuum assisted dressing after hernioplasty lowered the incidence of wound complications from 63.6 to 22 per cent ( $\mathrm{p}=0.020$ ), where the rates of dehiscence dropped from 39 to 9 per cent, skin and adipose tissue necrosis - from 18 to 9 per cent, wound abscess - from 6 to 4 per cent, formation of seromas - from 12 to 0 per cent and relapse of hernia - from 8 to 4 per cent. The study by Soares K.C. showed [29] that the incidence of infected wound complications lowered from 32 to 9 per cent.

Sources offer different takes on the clinical and economical efficacy of single-use preventative vacuum assisted dressings: thus some authors consider them viable [30,31] particularly for obese patients [32], others can not discern the difference in the results as compared with standard dressings [33-35].

Also, some authors recommend using interactive dressings based on carboxymethyl cellulose impregnated with silver ions as preventive measures, noting their high clinical efficacy as compared with standard dressings [36,37].

The goal of our pilot prospective comparative study was to evaluate the efficacy of various wound dressings in prevention of surgical site surface infections in high-risk orthopaedic patients.

\section{Materials and Methods}

The study analyzed the results of treatment of 30 patients who received medical care in City clinical hospital \#13 in September 2013-March 2014. Earlier the patients who were considered high-risk underwent hip or knee replacement. The risk factors were: revisional arthroplasty, concomitant obesity (BMI over $28 \mathrm{~kg} / \mathrm{m}^{2}$ ) and diabetes mellitus.

*Corresponding author: Obolenskiy VN, State financed educational institution Higher professional education institution Peoples' Friendship University of Russia, 117198, Moscow, Russian Federation, Tel: +7(916)172-44-30; E-mail: gkb13@ mail.ru

Received June 23, 2015; Accepted July 27, 2015; Published August 12, 2015

Citation: Obolenskiy VN, Golev SN, Zakirov II, Semenistyy AA (2015) Topical Negative Pressure Therapy and Interactive Dressings in Prevention of Wound Infections in High-Risk Orthopaedic Patients. J en Pract 3: 197. doi: 10.4172/23299126.1000197

Copyright: ( 2015 Obolenskiy VN, et al. This is an open-access article distributed under the terms of the Creative Commons Attribution License, which permits unrestricted use, distribution, and reproduction in any medium, provided the original author and source are credited. 
Citation: Obolenskiy VN, Golev SN, Zakirov II, Semenistyy AA (2015) Topical Negative Pressure Therapy and Interactive Dressings in Prevention of Wound Infections in High-Risk Orthopaedic Patients. J en Pract 3: 197. doi: 10.4172/2329-9126.1000197

Page 2 of 5

All patients received blood sugar normalization therapy, thromboembolism prevention treatment and perioperative preventive antibiotics for 24 hours; during the surgery all patients had Redon drain placed under the fascia which was later removed on day 3.

All patients were randomly divided into 3 groups of 10 , according to their hospital admission sequence.

Patients in group 1 ( 4 males, 6 females, average age $57.7 \pm 3.9$ years) had their wounds sutured and covered with cohesive interactive absorbent dressings based on sodium carboxymethyl cellulose impregnated with 1.2 per cent ionic silver solution and reinforced with fiber; the dressings were replaced on day 5 and completely removed on day 12 when the sutures were released (Figure 1).

Patients in group 2 ( 4 males, 6 females, average age $56.0 \pm 3.8$ years) had their wounds sutured and covered with single-use vacuum-assisted dressings; the dressings were replaced on day 5 and completely removed on day 12 when the sutures were released (Figure 2).

Patients in group 3 ( 3 males, 7 females; average age $54.8 \pm 2.9$ years)

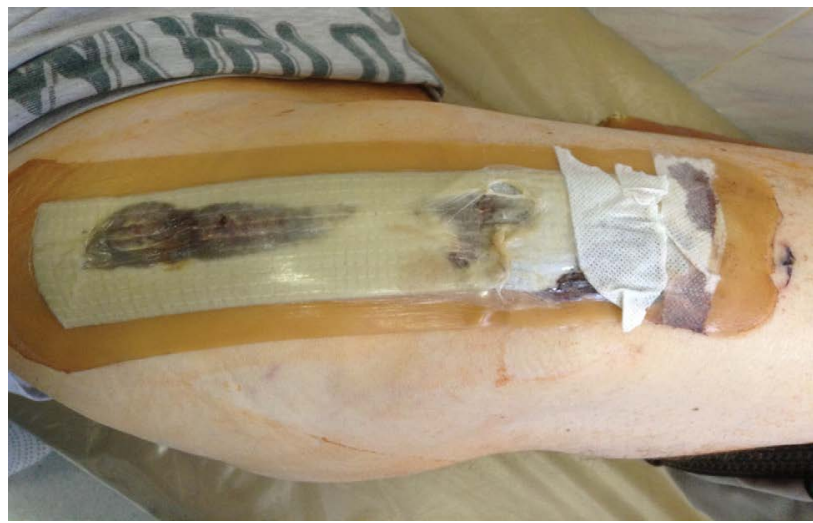

Figure 1a: Dressing before removal on day.

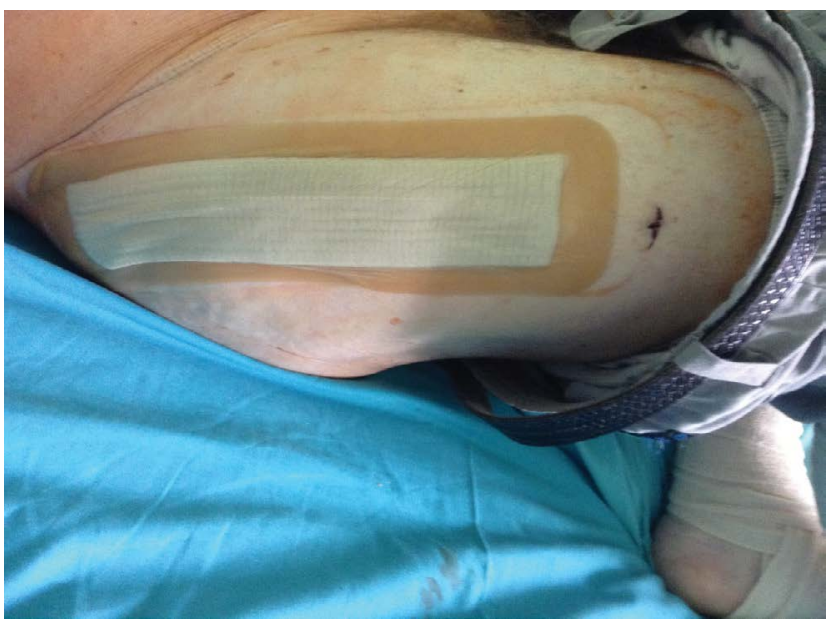

Figure 1c: New dressing. had their wounds sutured and covered with aseptic gauze dressings. Subsequently the incision zones were treated daily with povidone iodine solution and the dressings were replaced every day until the sutures were released (Figure 3).

\section{Results}

In group 1 the average bed stay amounted to $13.5 \pm 0.2$ days, no infections in the surgical area were observed in the following month after the treatment. In group 2 the average bed stay amounted to 14.8 \pm 0.8 days, no infections in the surgical area were observed in the following month after the treatment. In group 3 the average bed stay amounted to $14.8 \pm 0.8$ days, 3 cases of infection in the surgical area were observed in the form of wound abscesses and suture sinuses within 2-3 weeks after the treatment.

The cost of treatment with respect to dressings used and without notice to the cost of implants, follow-up admissions and treatment of patients with complications amounted to 61,268 rubles in group 1, 69,309 rubles in group 2 and 75,068 rubles in group 3.

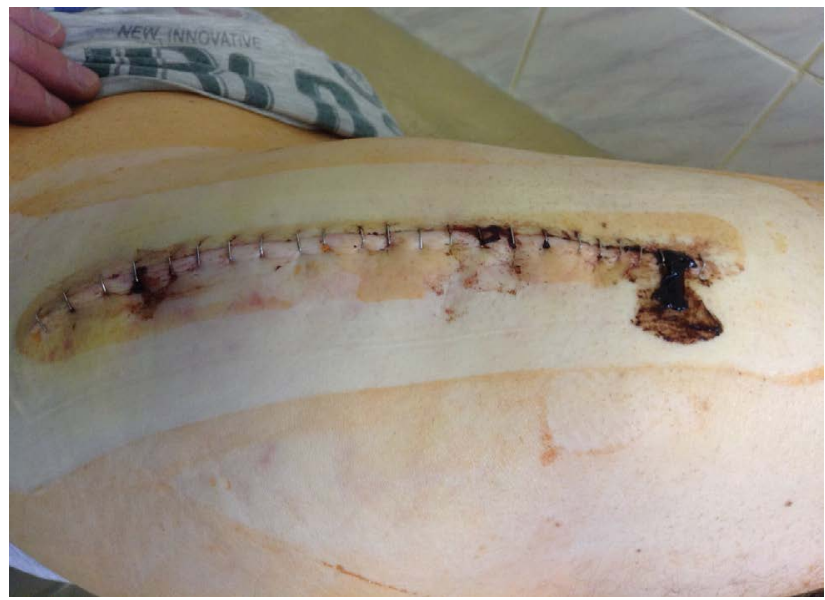

Figure 1b: Surgical site area on day 5 .

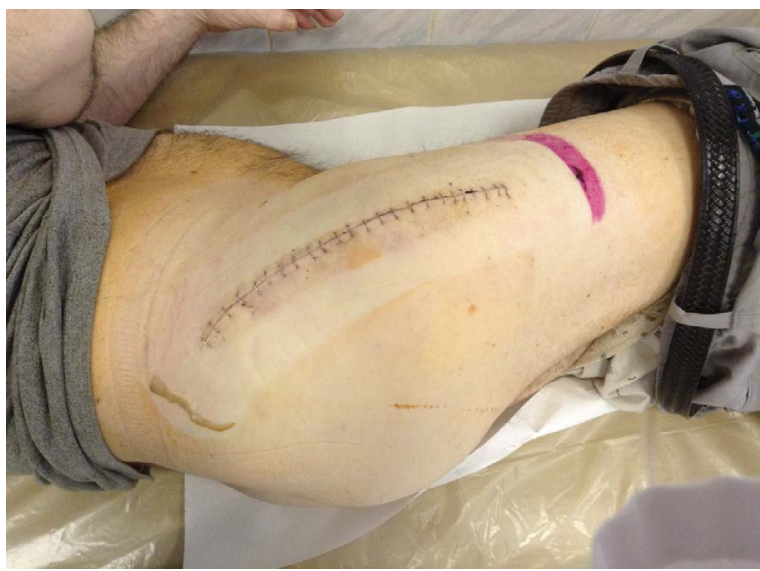

Figure 1d: Surgical site area before suture release. 
Citation: Obolenskiy VN, Golev SN, Zakirov II, Semenistyy AA (2015) Topical Negative Pressure Therapy and Interactive Dressings in Prevention of Wound Infections in High-Risk Orthopaedic Patients. J en Pract 3: 197. doi: 10.4172/2329-9126.1000197

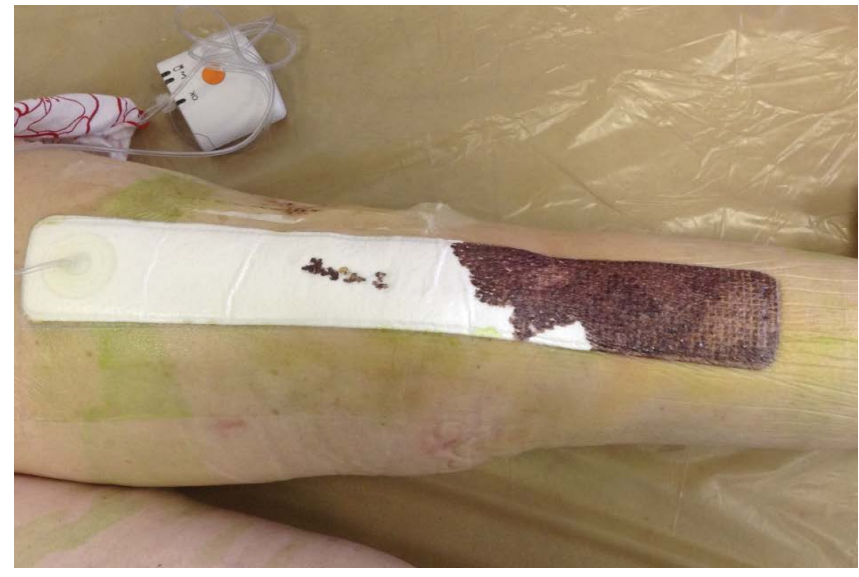

Figure 2a: Dressing before removal on day.

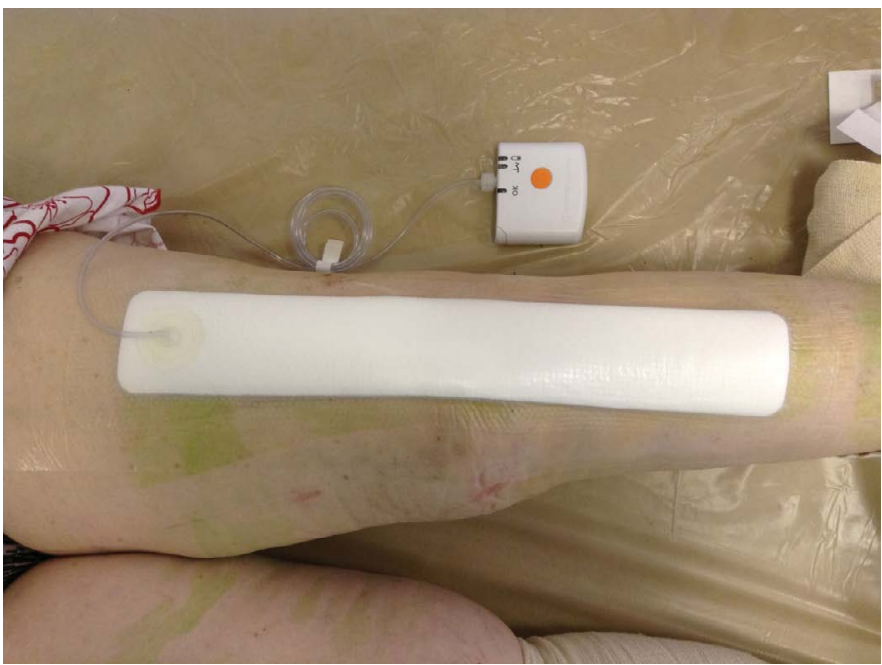

Figure 2c: New dressing.

In the course of the prospective follow-up in 3, 6, 12 and 18 months no cases of infectious complication in all patients of all three groups were observed.

Discussion: The use of interactive absorbent dressing based on carboxymethyl cellulose impregnated with silver ions and single-use vacuum-assisted dressings in early postoperative period can reduce the incidence of surgical site infections in high-risk orthopaedic patients as well as cut the costs.

The results are contrary to the opinion of some authors [33-35] with whom we disagree. Moreover, the results were better than that described by other authors [30-32,36,37]. This can be explained only by a small amount of our pilot study - certainly in the larger sample and

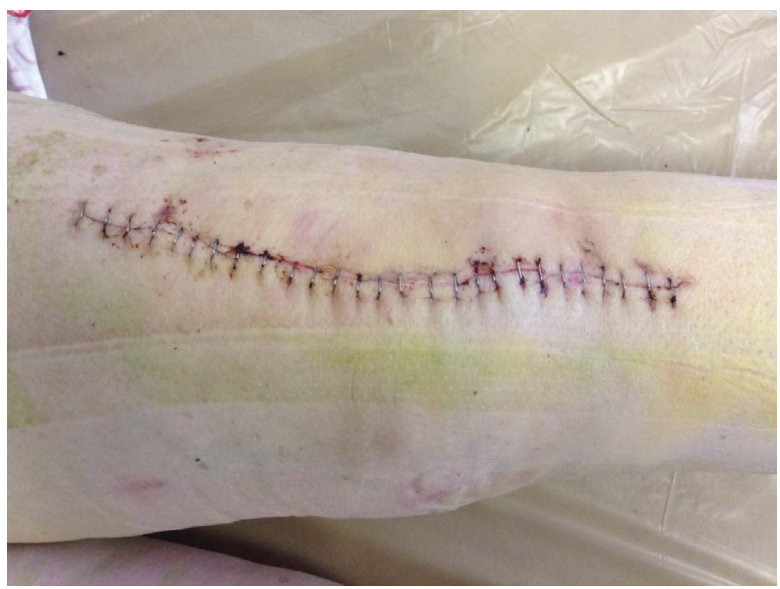

Figure 2b: Surgical site area on day.

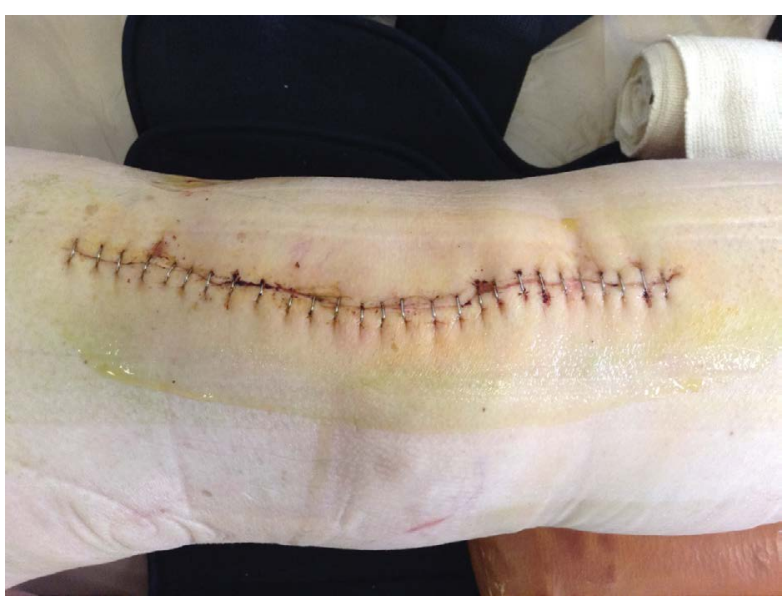

Figure 2d: Surgical site area before suture release.

in groups using interactive and vacuum-assisted dressings should be a certain percentage of complications.

To make solid conclusions it is required to conduct multi-center randomized study that would include a bigger number of patients.

\section{Conclusion}

Despite the small sample of patients obtained results allow us to recommend the use of interactive absorbent dressings of sodium carboxymethyl cellulose with silver ions and disposable vacuum assisted dressings in the early postoperative period in patients with orthopedic risk groups - revision arthroplasty, the accompanying obesity and diabetes. 
Citation: Obolenskiy VN, Golev SN, Zakirov II, Semenistyy AA (2015) Topical Negative Pressure Therapy and Interactive Dressings in Prevention of Wound Infections in High-Risk Orthopaedic Patients. J en Pract 3: 197. doi: 10.4172/2329-9126.1000197

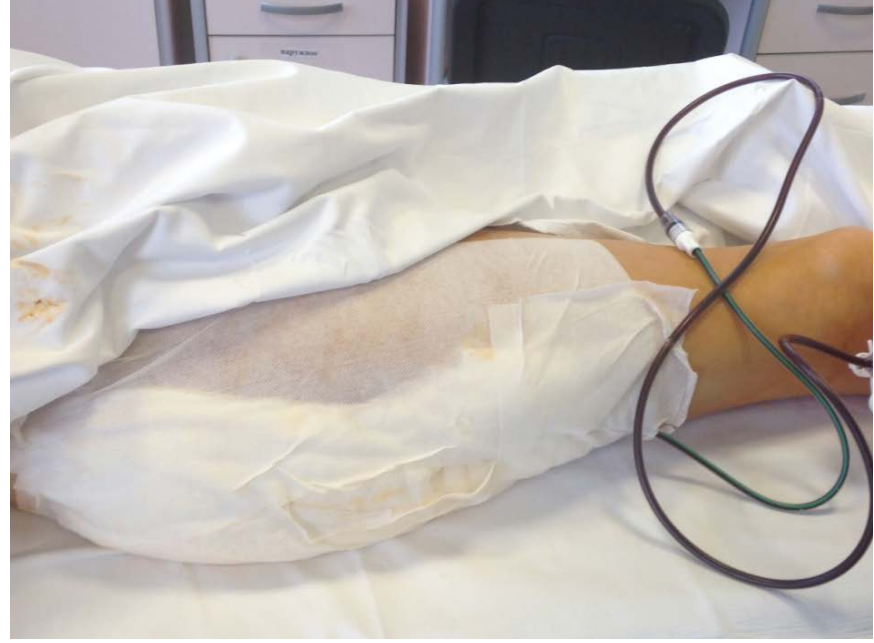

a

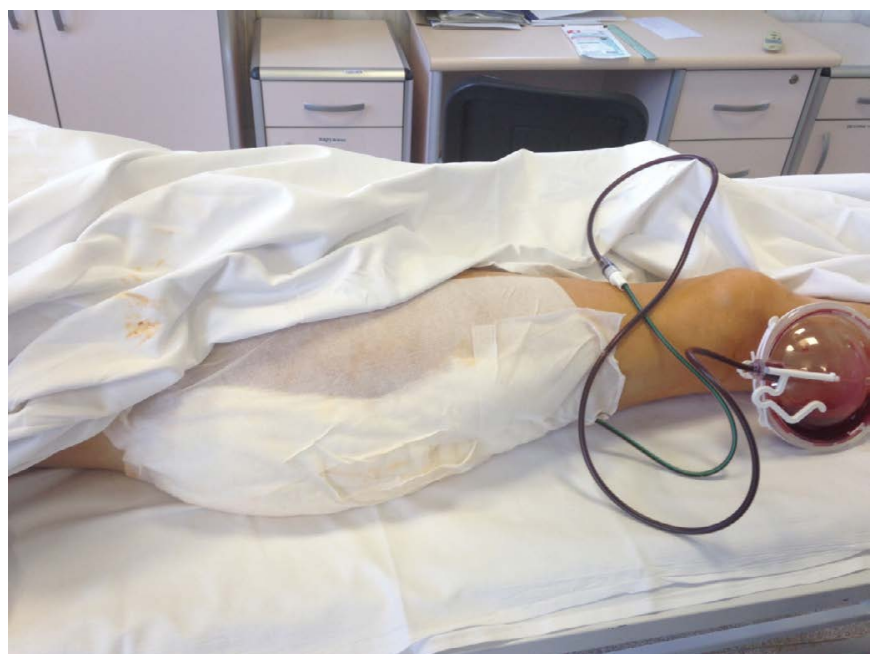

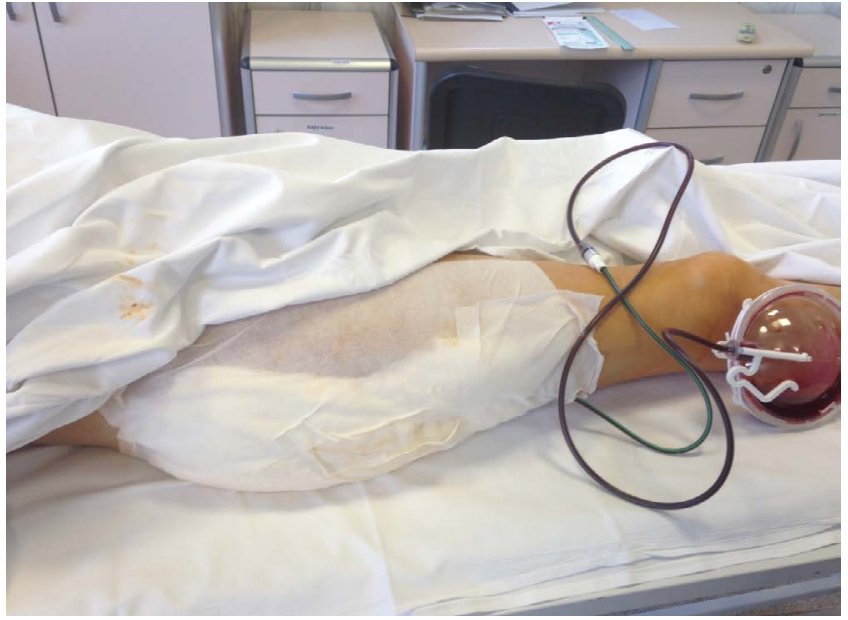

b

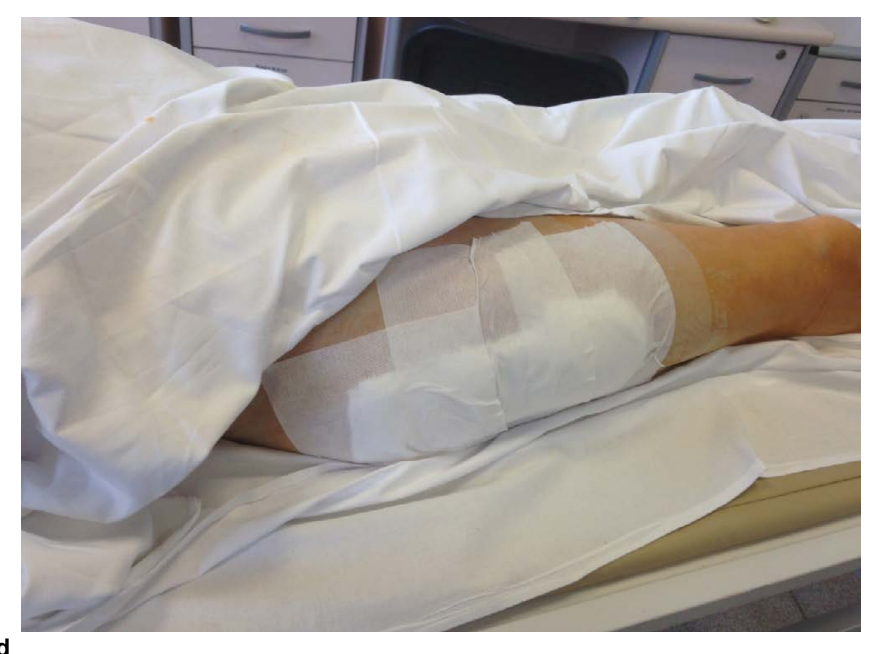

Figure 3:a-d: stages of gauze dressing application after the deep-seated drainage tube was removed.

\section{References}

1. Adeli B, Parvizi J (2012) Strategies for the prevention of periprosthetic joint infection. J Bone Joint Surg Br 94: 42-46.

2. Sukeik M, Haddad FS (2009) Two-stage procedure in the treatment of late chronic hip infections--spacer implantation. Int J Med Sci 6: 253-257.

3. Kuper M, Rosenstein A (2008) Infection prevention in total knee and total hip arthroplasties. Am J Orthop (Belle Mead NJ) 37: E2-5.

4. Rezapoor M, Parvizi J (2015). Prevention of Periprosthetic Joint Infection. J Arthroplasty.

5. Tande AJ, Patel R (2014) Prosthetic joint infection. Clin Microbiol Rev 27: $302-$ 345.

6. Sankar S, Crudden J, Meisel HJ (2014). Examining the in-vitro antimicrobial and in-vivo anti-biofilm efficacy of a PEEK-silver zeolite composite in tackling surgical site spine infections. EBJIS F0 72: 80.

7. Lindeque B, Hartman Z, Noshchenko A, Cruse M (2014) Infection after primary total hip arthroplasty. Orthopedics 37: 257-265.

8. Frank RM, Cross MB, Della Valle CJ (2015) Periprosthetic joint infection: modern aspects of prevention, diagnosis, and treatment. J Knee Surg 28: 105-112.
9. Yin JM, Liu ZT, Zhao SC, Guo YJ (2013) Diagnosis, management, and prevention of prosthetic joint infections. Front Biosci (Landmark Ed) 18: 1349$1357 . t$

10. Morrison TA, Figgie M, Miller AO, Goodman SM (2013) Periprosthetic joint infection in patients with inflammatory joint disease: a review of risk factors and current approaches to diagnosis and management. HSS J 9: 183-194.

11. Baek SH (2014) Identification and preoperative optimization of risk factors to prevent periprosthetic joint infection. World J Orthop 5: 362-367.

12. Al Mohajer M, Darouiche RO (2014) The expanding horizon of prosthetic joint infections. J Appl Biomater Funct Mater 12: 1-12.

13. Wu C, Qu X, Liu F, Li H, Mao Y, et al. (2014) Risk factors for periprosthetic joint infection after total hip arthroplasty and total knee arthroplasty in Chinese patients. PLoS One 9: e95300.

14. Kuiper JW, Willink RT, Moojen DJ, van den Bekerom MP, Colen S (2014) Treatment of acute periprosthetic infections with prosthesis retention: Review of current concepts. World J Orthop 5: 667-676.

15. Bedair H, Goyal N, Dietz MJ, Urish K, Hansen V, et al. (2015) A History of Treated Periprosthetic Joint Infection Increases the Risk of Subsequent Different Site Infection. Clin Orthop Relat Res 473: 2300-2304. 
Citation: Obolenskiy VN, Golev SN, Zakirov II, Semenistyy AA (2015) Topical Negative Pressure Therapy and Interactive Dressings in Prevention of Wound Infections in High-Risk Orthopaedic Patients. J en Pract 3: 197. doi: 10.4172/2329-9126.1000197

Page 5 of 5

16. Peel TN, Dowsey MM, Daffy JR, Stanley PA, Choong PF, et al. (2011) Risk factors for prosthetic hip and knee infections according to arthroplasty site. $J$ Hosp Infect 79: 129-133

17. Carroll K, Dowsey M, Choong P, Peel T (2014) Risk factors for superficial wound complications in hip and knee arthroplasty. Clin Microbiol Infect 20: 130-135.

18. Jonsson EÖ, Johannesdottir H, Robertsson O, Mogensen B (2014) Bacterial contamination of the wound during primary total hip and knee replacement. Median 13 years of follow-up of 90 replacements. Acta Orthop 85: 159-164.

19. Kerkhoffs GM, Servien E, Dunn W, Dahm D, Bramer JA, et al. (2012) The influence of obesity on the complication rate and outcome of total knee arthroplasty: a meta-analysis and systematic literature review. J Bone Joint Surg Am 94: 1839-1844.

20. Jämsen E, Nevalainen $P$, Eskelinen A, Huotari K, Kalliovalkama J, et al (2012) Obesity, diabetes, and preoperative hyperglycemia as predictors of periprosthetic joint infection: a single-center analysis of 7181 primary hip and knee replacements for osteoarthritis. J Bone Joint Surg Am 94: e101.

21. Jørgensen PH, Gromov K, Søballe K (2007) [Prevention of prosthesis infections]. Ugeskr Laeger 169: 4159-4163.

22. Shuman EK, Malani PN (2011) Prevention and management of prosthetic joint infection in older adults. Drugs Aging 28: 13-26.

23. Lehner B, Bernd L (2006) [V.A.C.-instill therapy in periprosthetic infection of hip and knee arthroplasty]. Zentralbl Chir 131 Suppl 1: S160-164.

24. Kelm J, Schmitt E, Anagnostakos K (2009) Vacuum-assisted closure in the treatment of early hip joint infections. Int J Med Sci 6: 241-246.

25. Schintler MV (2012) Negative pressure therapy: theory and practice. Diabetes Metab Res Rev 28 Suppl 1: 72-77.

26. C. Willy (2006) The Theory and Practice of Vacuum Therapy 405.

27. Pachowsky M, Gusinde J, Klein A, Lehrl S, Schulz-Drost S, et al. (2012) Negative pressure wound therapy to prevent seromas and treat surgical incisions after total hip arthroplasty. Int Orthop 36: 719-722.
28. Condé-Green A, Chung TL, Holton LH 3rd, Hui-Chou HG, Zhu Y, et al. (2013) Incisional negative-pressure wound therapy versus conventional dressings following abdominal wall reconstruction: a comparative study. Ann Plast Surg 71: 394-397.

29. Soares KC, Baltodano PA, Hicks CW, Cooney CM, Olorundare IO, et al. (2015) Novel wound management system reduction of surgical site morbidity after ventral hernia repairs: a critical analysis. Am J Surg 209: 324-332.

30. Ingargiola MJ, Daniali LN, Lee ES (2013) Does the application of incisional negative pressure therapy to high-risk wounds prevent surgical site complications? A systematic review. Eplasty 13: e49.

31. Payne C, Edwards D (2014) Application of the Single Use Negative Pressure Wound Therapy Device (PICO) on a Heterogeneous Group of Surgical and Traumatic Wounds. Eplasty 14: e20.

32. Webster J, Scuffham P, Stankiewicz M, Chaboyer WP (2014). Negative pressure wound therapy for skin grafts and surgical wounds healing by primary intention. Cochrane Database Syst Rev.

33. Dumville JC, Walter CJ, Sharp CA, Page T (2011). Dressings for the prevention of surgical site infection. Cochrane Database Syst Rev 6: CD003091.

34. Masden D, Goldstein J, Endara M, Xu K, Steinberg J, et al. (2012) Negative pressure wound therapy for at-risk surgical closures in patients with multiple comorbidities: a prospective randomized controlled study. Ann Surg 255: 10431047.

35. Gillespie BM, Rickard CM, Thalib L, Kang E, Finigan T, et al. (2015) Use of Negative-Pressure Wound Dressings to Prevent Surgical Site Complications After Primary Hip Arthroplasty: A Pilot RCT. Surg Innov.

36. Jurczak F, Dugré T, Johnstone A, Offori T, Vujovic Z, et al. (2007) Randomised clinical trial of Hydrofiber dressing with silver versus povidone-iodine gauze in the management of open surgical and traumatic wounds. Int Wound J 4: 66-76.

37. Marinović M, Cicvarić T, Grzalja N, Bacić G, Radović E (2011) Application of wound dressing Molndal technique in clean and potentially contamined postoperative wounds--initial comparative study. Coll Antropol 35 Suppl 2: 103106. 